\title{
A TRANSIÇÃO AGROECOLÓGICA NA PRODUÇÃO CAMPONESA
}

\author{
THE AGROECOLOGICAL TRANSITION IN PEASANT PRODUCTION \\ LA TRANSICIÓN AGROECOLÓGICA EN LA PRODUCCIÓN CAMPESINA \\ Maria Aline da Silva Batista - Doutoranda em Geografia - Universidade \\ Federal do Ceará - Fortaleza - Ceará - Brasil \\ m_aline@ifce.edu.br
}

\begin{abstract}
Alexandra Maria de Oliveira - Universidade Federal do Ceará - Fortaleza - Ceará - Brasil
alexandra.oliveira@ufc.br
\end{abstract}

\section{Resumo}

0 presente artigo discute a importância da transição agroecológica na produção camponesa, na região norte do Ceará. Tendo por base os teóricos que pensam a Agroecologia como caminho para 0 desenvolvimento rural, procuramos identificar as estratégias empreendidas pelos camponeses e os resultados decorrentes. A metodologia utilizada contou com revisão bibliográfica e trabalhos de campo. Foram realizadas visitas em duas unidades de produção e entrevistas semiestruturadas gravadas com os camponeses e técnicos agrícolas envolvidos. Verificamos que as técnicas agroecológicas contribuem para a recuperação dos solos e são mais eficientes que as práticas convencionais nos períodos de estiagem. Além disso, foi constatado que houve uma maior diversificação da produção, o que reflete na melhoria da alimentação e, consequentemente, na soberania alimentar das famílias envolvidas.

Palavras-chave: Transição agroecológica, campesinato, soberania alimentar, Ceará.

\section{Abstract}

The present article discusses the importance of the agroecological transition in peasant production, in the northern region of Ceará. Based on the theorists who research Agroecology as a path to rural development, we seek to identify the strategies undertaken by peasants, as well as the results derived. The methodology used included bibliographical review and fieldwork. Visits were carried out in two production units and semistructured interviews were recorded with the farmers and agricultural technicians involved. We verified that agroecological techniques are contributing to soil recovery and are more efficient than the conventional practices in the dry season. Besides this, it was found that there was a greater diversification of production, which reflects in the improvement of feed and, consequently, in the food sovereignty of the families involved. Keywords: Agroecological transition, peasantry, food sovereignty, Ceará.

\section{Resumen}

Este artículo discute la importancia de la transición agroecológica en la producción campesina, en la región norte de Ceará. Basándonos en teóricos que piensan en la Agroecología como camino para el desarrollo rural, buscamos identificar las estrategias emprendidas por los campesinos y los resultados provenientes. La metodología usada contó con una revisión bibliográfica y trabajos de campo. Se realizaron visitas a dos unidades de producción y entrevistas semi-estructuradas grabadas a los campesinos y técnicos agrícolas involucrados. Verificamos que las técnicas agroecológicas contribuyen con la recuperación de los suelos y son más eficientes que las prácticas convencionales en los períodos de sequía. Además de eso, se constató una mayor diversificación de la producción, lo que repercute en la mejoría de la alimentación y consecuentemente, en la soberanía alimentar de las familias.

Palabras clave: Transición agroecológica, campesinado, soberanía alimentaria, Ceará. 
Introdução

O estudo sobre a produção agroecológica, a partir do arsenal teórico da Geografia, busca entender como as mudanças nas técnicas de produção alteram as relações sociais estabelecidas no espaço. Diante disso, investigamos os caminhos trilhados por camponeses do Ceará, a fim de identificar formas de produção agrícola compatíveis com o projeto de vida camponês. Nesta linha de trabalho, destacamos a Rede de Agricultores Agroecológicos e Solidários do Território dos Vales do Curu e Aracatiaçu.

As duas famílias entrevistadas tiveram os primeiros contatos com as técnicas denominadas agroecológicas em uma formação de Agentes Multiplicadores de Agroecologia, realizada nos anos de 2004 e de 2005, pelo Centro de Estudos do Trabalho e de Assessoria ao Trabalhador (CETRA), com apoio financeiro da Organização Não Governamental (ONG) Manos Unidas.

A metodologia utilizada nesta pesquisa contou com revisão bibliográfica sobre o tema e visitas técnicas, durante as quais foram realizadas entrevistas semiestruturadas.

Transição agroecológica: o caminho para a autonomia camponesa

Os princípios da Agroecologia baseiam-se na observação realista e minuciosa da natureza, seja pelos camponeses, seja pelos cientistas. Com base no conhecimento dos mecanismos naturais, são formuladas as técnicas que melhor exploram as potencialidades do ambiente, sem acarretar a degradação do mesmo. A produção de alimentos é um fatorchave no equilíbrio da sociedade e ninguém está imune à crise na produção alimentícia. A transição agroecológica é, portanto, uma questão de interesse social, não podendo ser fruto unicamente de iniciativas externas, mas de ações locais, que devem nascer no seio das comunidades.

Percebemos nos discursos dos sujeitos investigados neste trabalho que para a maioria dos camponeses que aceitaram experimentar a vivência de um processo de transição agroecológica, o mais difícil foi conviver com as críticas de familiares e de pessoas da comunidade, com a falta de apoio de políticas públicas e com a falta de informação por parte do consumidor.

Em um dos depoimentos pudemos constatar o embate gerado pela iniciativa de promover uma mudança, ainda que pontual: "[...] eu fui 
muito criticado pelo povo da comunidade, pela família [...]. Queriam até arrumar hospital pra mim que eu tava ficando doido, mas isso aí não me impediu em nada.” (Z. J., camponês do Assentamento Várzea do Mundaú - Trairi-CE, 2014).

De igual modo, essa dificuldade foi notada por Batista (2014), ao estudar os camponeses cearenses nos municípios de Trairi e Tururu, e por Schneider (2014), ao estudar os camponeses pomeranos do município de São Lourenço do Sul, no Rio Grande do Sul. Nota-se que o processo de transição agroecológica corresponde a avanços progressivos, partindo da mudança da concepção da relação com a natureza.

O curso de Formação em Agentes Multiplicadores de Agroecologia seguiu a leitura da Agroecologia descrita por Toledo (2016), na qual ela é desenvolvida como ciência política e socialmente comprometida, como prática com suas inovações tecnológicas e como movimento de transformação social. No processo, o diálogo foi acontecendo aos poucos, sem o abandono do conhecimento ancestral, no qual muitas vezes a explicação para os fenômenos da natureza ganha uma conotação mítica, conforme se pode observar no depoimento de M. G. P.:

A aula desse professor [do curso de formação] alertou para o que a gente estava fazendo. A gente estava matando noventa espécies para cultivar duas ou três, aí foi que eu me dei conta que as espécies, não são só as plantas, tem as minhocas, tem as aranhas, tem toda aquela cadeia ali que está fazendo com que a terra não acabe de novo, porque você sabe que o fogo além de matar os insetos também mata o sangue da terra - quando você queima uma terra, aquela terra vira areia, então você tirou todo o sangue da terra -, e foi daí que eu comecei a me interessar mais, a deixar de queimar, a deixar de usar veneno, a respeitar mais o meio ambiente (M. G. P., Assentamento Novo Horizonte - Tururu-CE, 2014).

É no confronto dos conhecimentos recém-adquiridos com as explicações mitológicas sobre a natureza que as técnicas agroecológicas ganham sentido para os camponeses que, embora até certo ponto da vida desconhecessem a Agroecologia como ciência, recordam o conhecimento que foi lhes repassado ao longo das gerações e deslegitimado pelo discurso da modernidade.

A Agroecologia encontra espaço na agricultura camponesa porque resgata os ensinamentos ancestrais que os camponeses sempre cultivaram, não negando sua cultura e nem os reduzindo a mão de obra da atividade 
agrícola. Portanto, o papel dos agrônomos e demais técnicos não seria o de ditar a melhor forma de produzir, mas acompanhar o camponês nesse processo, compreendendo seus interesses e dando-lhe condições de melhor utilizar o conhecimento que já possui (Dufumier, 2011).

Em estudo sobre as formas de produção agroecológica empreendidas pelos camponeses do Alto Sertão e Zona da Mata da Paraíba, Marcos (2007) constata que os camponeses adaptaram os ensinamentos técnicos à sua realidade e possibilidade, modificando as práticas a fim de ter melhor resultado. Segundo a autora, os camponeses garantem a sua autossustentabilidade complementando o conhecimento técnico com os saberes locais (Marcos, 2007).

É ciente disso que a transição agroecológica é proposta por Gliessman (2000) em etapas, nem sempre lineares, as quais consistem em: $1^{\circ}$ ) mudança dos valores que orientam as decisões de produção; $2^{\circ}$ ) manejo integrado de pragas e da fertilidade do solo; $3^{\circ}$ ) substituição de agroquímicos por insumos ambientalmente benéficos; e $4^{\circ}$ ) redesenho do agroecossistema, para que ele possa ser autossustentado.

As etapas da transição não necessariamente ocorrem nessa ordem, mas geralmente obedecem a um padrão de substituição gradual de antigas práticas e insumos por outros mais sustentáveis. São os resultados das experiências que vão ditar a velocidade da mudança, pois alguns cultivos podem se adaptar bem sem agrotóxicos, enquanto outros podem ser mais difíceis de serem produzidos.

Sem dúvida, a etapa mais árdua é a inicial, pois o solo, geralmente bastante degradado, demora certo tempo para recuperar a fertilidade natural, o que pode ocasionar a diminuição da produtividade. Em contrapartida, após o período de estabilização, a produtividade aumenta e consequentemente o retorno financeiro também. Os camponeses entrevistados enfatizaram bem esta questão:

A Agroecologia é um passo muito lento para se começar a fazer e as pessoas gostam de dinheiro imediato. Isso precisa do desenrolar de um bom tempo até que a mata cresça de novo, até as plantas atingirem a fase adulta para a gente começar a tirar o fruto. A gente faz um trabalho que é para o resto da vida, então as pessoas acham que está custando e prefere vender diária ou o produto para alguém. (A. M. A., Assentamento Várzea do Mundaú - Trairi-CE, 2014). 
As propriedades onde dominam os policultivos, em geral, são mais eficientes do ponto de vista econômico e ambiental. Ainda de acordo com Altieri (2012, p. 170) “os policultivos, por exemplo, quando comparados às monoculturas, apresentam maior estabilidade de produção e taxas menores de queda de estabilidade durante a seca”, o que é constatado também pelos camponeses entrevistados, como no depoimento que segue:

Nós brocávamos uma área bem grande para plantar milho, feijão e mandioca. Agora eu trabalho numa área de 160 metros de comprimento por 20 de largura, é uma diferença muito grande, e dentro dessa pequena área tem toda essa produção, tem ovo, tem frango, tem banana, tem macaxeira, tem cheiro-verde, tem peixe, tem muito mais variedade, tem cana-de-açúcar, tem uma infinidade de coisas. (M.G. P., Assentamento Novo Horizonte - Tururu-CE, 2014).

A variedade na produção repercute na alimentação das famílias camponesas. O autoconsumo é um ganho que não pode ser mensurado, mas sem dúvida melhora a qualidade de vida e garante a soberania alimentar, como se nota em depoimento de camponês sobre as mudanças que a produção agroecológica trouxe para sua vida e família:

Uma delas [das mudanças] é na saúde da família e no hábito alimentar que agora a gente tem mais condição, [...] a gente tem várias plantas medicinais no sítio e a gente estando consumindo saudável até o psicológico da gente ajuda a dizer que a gente tem saúde, e de outra forma é a quantidade de alimentação que a gente tem, se a gente for dez vezes ao sítio, a gente traz comida dez vezes, na hora que a gente vai para o sítio a gente traz alguma coisa para comer, é diferente de quando a gente comia só quando vinha no mercado levava pra casa... Isso é algumas das mudanças! (A. M. A. Assentamento Várzea do Mundaú - Trairi-CE, 2014).

A segurança e a soberania alimentar são fatores-chave para a permanência das famílias no campo. A soberania alimentar diz respeito não só à garantia de alimentos em quantidade e qualidade suficientes ao suprimento das necessidades nutricionais da população, mas à autonomia dos povos em produzir esses alimentos. Tal conceito está relacionado à apropriação do conhecimento, das técnicas e dos meios de produção, inclusive a terra, para a produção agrícola (Stedile; Carvalho, 2012).

Um caminho que tem sido trilhado e se mostrado promissor na busca pela soberania alimentar, no Ceará e em outras partes do Brasil, 
conforme revelado por Oliveira e Sampaio (2017), é a educação do campo, que tem efetivado o compromisso de consolidar os valores defendidos pelos movimentos sociais, através da aplicação prática dos princípios agroecológicos por meio de projetos de hortas escolares.

A disseminação do conhecimento agroecológico tem se mostrado uma estratégia viável de transformação social e consolidação do território camponês. Ela proporciona maior controle da produção, melhores condições de vida e maior vínculo com a terra.

As estratégias desenvolvidas pelos camponeses a fim de conquistarem mais qualidade de vida no campo e mais espaço na sociedade são as mais variadas possíveis e seguem percursos diversos, pois não existe receita pronta a seguir. As iniciativas partem dos anseios da comunidade, considerando suas condições materiais (Rosset, 2016).

No caso dos camponeses entrevistados, as experiências foram colocadas em prática aos poucos, de forma que algumas foram inteiramente abandonadas por se mostrarem inviáveis, outras parcialmente aproveitadas e outras bem sucedidas. Os resultados que se tem hoje são frutos de um longo caminho de experimentação que ainda está em curso. A camponesa M. G. P. relata o percurso vivenciado por ela e outros vizinhos que também fazem parte do grupo de feirantes da Feira Agroecológica e Solidária da cidade de Itapipoca-CE:

Nós já passamos por um bocado de coisas aqui, primeiro nós tínhamos uma horta, ali no caminho do rio, junto com outros agricultores. Eu trabalhava ali com banana, mamão, um monte de tipo de fruta, com verdura, lá tinha verdura para vender mesmo, todo dia tinha um vendedor de verdura... Aí, depois de passarmos um tempo lá, fizemos uma horta de planta medicinal lá do outro lado, passamos um tempo com ela lá também, mas não deu certo porque era longe de casa, irrigação mal feita, apareceu um monte de problemas. Depois, quando foi um dia veio um rapaz da Emater-Ce oferecendo um projeto de mandala para cá. Era um projeto pequeno para fazer um tanque e dar aulas para o pessoal daqui da região do semiárido. Era bom aqui porque era mais próximo e de fácil acesso para o pessoal de Fortaleza vim dar as aulas e ia ficar o tanque aqui pra nós, mas o melhor de tudo foi mesmo a aula, porque o tanque a gente pode conseguir comprar, mas a aula é diferente, né? Essa mandala daqui era para seis famílias, mas só que a gente não arranjou as seis famílias, então ficou só eu, minha comadre e o meu irmão. Só que o sistema era muito fraco, a água não dava para todo mundo, aí eu saí e deixei a mandala lá e arrumei um recurso 
próprio e fiz a minha. (M. G. P., camponesa do Assentamento Novo Horizonte - Tururu-CE, 2014).

Outro desafio que se coloca à disseminação da Agroecologia no Ceará é que a maioria das experiências é advinda de projetos, muitas vezes de curta duração. Nesse caso, quando o recurso acaba ou quando surgem problemas que não haviam sido pensados na proposta original fica difícil a resolução, pois não há apoio político e financeiro.

\section{Experiências de transição agroecológica na região norte do Ceará}

As experiências de produção agroecológica entre os camponeses entrevistados surgiram em diferentes contextos. As diferenças de condições naturais, econômicas, de estrutura familiar, de grau de engajamento em movimentos sociais não foram maiores do que o ponto em comum que os uniram: o vínculo com a terra, e derivado disso, a certeza de que é preciso cuidá-la melhor.

No grupo de feirantes investigados, oito são assentados, um proprietário e um mutuário. O tamanho das unidades de produção agroecológica varia entre 0,25 a quatro hectares, nas quais a mão de obra utilizada é predominantemente familiar, sendo contratado pessoal "de fora" para serviços esporádicos, como a "limpa do roçado" e a colheita, nos períodos de pico da lavoura. O canal de comercialização mais expressivo é a venda direta nas Feiras Agroecológicas e Solidárias.

As estratégias de produção agroecológica são variadas, uma vez que cada família tem suas especificidades, mas a tecnologia social responsável pela maior parte da produção é o quintal produtivo.

O quintal produtivo é um sistema de policultivos, preferencialmente cultivado próximo à residência, sendo, muitas vezes, uma extensão da casa. Por isso, o seu valor simbólico para a família, sobretudo para as mulheres, que o têm como despensa viva para sua prática cotidiana de preparo dos alimentos. O quintal representa, também, valor econômico por significar tanto soberania alimentar, como fonte de renda para a família; e tem valor ecológico, por ser espaço de experimentação de novas práticas e de perpetuação das práticas tradicionais.

Outras tecnologias sociais como a mandala e o PAIS (Produção Agroecológica Integrada e Solidária) também são empregadas por alguns camponeses. A mandala é um sistema de produção agrícola, no qual as 
plantas são cultivadas em círculos concêntricos a uma fonte de água. Nesse sistema, a ideia é buscar o máximo de aproveitamento das interações entre as espécies e da eficiência do uso da água.

O reservatório de água construído no centro deve servir tanto para a irrigação do sistema, como para a criação de peixes, os quais desempenham o papel de produtores de matéria orgânica, enriquecendo, assim, a água que será usada para irrigar as plantas, além de serem outra fonte de renda e alimento para a família. Nesse sistema de produção, a distribuição das culturas nos círculos obedece a critérios de necessidade de água e de mão de obra. Nos primeiros círculos, próximos ao tanque, devem ser cultivadas as hortaliças para consumo da família, pois esse tipo de planta necessita de cuidados mais constantes e de mais irrigação; do quarto ao oitavo círculo devem ser cultivadas culturas comerciais, como feijão, milho, fruteiras e raízes; e no nono círculo devem ser plantadas espécies que funcionem como cerca viva, desempenhando o papel de proteger a mandala, especialmente do vento e da polinização externa.

Durante os trabalhos de campo, tivemos a oportunidade de conhecer três unidades de produção. Visitamos o quintal produtivo e o sistema PAIS no Assentamento Várzea do Mundaú, em Trairi, da família dos camponeses Z. J. e F. M; visitamos também a mandala/quintal produtivo da família da dona M. G. P., e a Mandala onde trabalham a família da dona F. e a família do Sr. R. P, do assentamento Novo Horizonte, em Tururu.

No caso da mandala da camponesa M. G. P., no Assentamento Novo Horizonte, o sistema de produção não possui formato circular, tendo em vista as possibilidades do espaço físico da família. O terreno que a família dispunha para fazer a experiência era retangular, medindo 20 metros de largura por 160 metros de comprimento. No entanto, a questão da forma não foi impedimento para que a técnica fosse empregada e obtivesse êxito.

A camponesa M. G. P. conta que a produção foi se dando aos poucos, por meio de muitas experimentações. A partir das suas observações e do resultado de suas experiências, ela descobriu que a proposta da ordem de disposição das plantas nos círculos não era a mais apropriada à sua realidade, pois mesmo tendo construído dois tanques na mandala, onde cria peixes da espécie tilápia, nem sempre a água dos tanques era suficiente para aguar as plantas, sem comprometer a criação dos peixes. Por isso, ela optou por cultivar bananas (cultura comercial) e não hortaliças na área mais próxima aos tanques. Ela explicou que: 
Nem todas as plantas são irrigadas, porque a água é muito limitada, eu tenho dois tanques aqui que têm peixe e aí quando chega a certa altura não pode mais tirar água, senão morre o peixe, aí é muito ruim para plantar verdura e também porque a água é puxada a motor e quando falta energia não tem água, é complicado demais. (M. G. P. Assentamento Novo Horizonte - Tururu-CE, 2014).

Apesar da dificuldade de água ressaltada pela camponesa, é válido lembrar que a seca dos últimos cinco anos (2012 a 2017) não tem impedido a produção, nos quintais produtivos, que em nada lembra o cenário típico de seca vivenciada.

Não são apenas as condições ambientais, como solo, vegetação e recursos hídricos que ditam as possibilidades de produção, mas também a estrutura familiar, pois ela condiciona a disponibilidade de mão de obra. A respeito da organização do trabalho na mandala, M. G. P. conta ainda que é preciso adaptar a produção agroecológica às possibilidades da força de trabalho da família. Já que no seu caso essa força de trabalho é reduzida, a camponesa elimina as técnicas que demandam mais esforço:

O certo do projeto onde nós estudamos era pra alimentar também os peixes com os restos de plantas da mandala, mas como o tempo é pouco a gente compra a ração e bota pra eles, porque já tem também as galinhas que eu preciso tá todo dia atrás de mato pra botar no chiqueiro, aqui mesmo [nos tanques] eu só boto mais a ração comprada, difícil eu botar um mato pra eles... A gente também cata as lagartas já que a gente não pulveriza, aí bota e eles comem, comem folhas de couve, coisas assim, eles se alimentam também da flor das bananeiras [que caem no tanque], as galinhas se alimentam com ração comprada e também com as coisas da mandala, as folhas, restos de comida, por exemplo; ontem eu arranquei macaxeira para fazer os bolos e levar para a feira, e o que sobrou, eu cozinhei e botei pra elas também, é assim aqui, não vai nada pro lixo. (M. G. P. Assentamento Novo Horizonte - Tururu-CE, 2014).

A camponesa demonstra que existe uma integração das atividades de produção realizadas na mandala, onde uma complementa a outra e todo recurso é aproveitado: "não vai nada pro lixo". Apesar disso, reconhece que nem sempre é possível realizar o trabalho do jeito "certo do projeto”, em virtude da insuficiência de mão de obra familiar, sendo preciso introduzir energia externa ao agroecossistema, “a ração comprada”, no caso.

Na mandala da família, além da criação de peixes, há criação de aves, cultivo de plantas ornamentais, medicinais, hortaliças e frutas. A 
diversificação garante alimentos de qualidade para o abastecimento da mesa da família e da feira agroecológica. A variedade de plantas cultivadas garante além de serviços ecológicos, como o aumento da biomassa, maior segurança econômica, especialmente, em tempos de estiagem.

O estágio de transição agroecológica vivenciado pela família em questão mostra que muitos avanços já foram alcançados, como o aumento da fertilidade do solo e a capacidade de retenção de água por mais tempo. A camponesa M. G. P. mostra uma das técnicas que aprendeu e adaptou com sucesso ao seu quintal, conforme seu depoimento:

Você vê aqui que nós estamos num alto, mas olha o tamanho dos cachos de banana, isso é porque eu pago um rapaz para cavar um meio metro ou menos, uns trinta centímetros, aí eu pego o resto da bananeira, o resto do milho, todos esses restos a gente pega junto com casca de coco, enche a vala, quando a vala tá cheia eu cubro e faço os canteiros em cima. Esse sistema não era nem pra nós, era lá pra o semiárido, mas o sistema é tão bom que eu adotei aqui. Qualquer canto que você fizer o canteiro desse jeito ele vai dar certo. (M. G. P., camponesa do Assentamento Novo Horizonte - Tururu-CE, 2014).

A técnica a qual a camponesa está se referindo diz respeito ao aumento da quantidade de nutrientes do solo e, consequentemente, de sua fertilidade. Esse tipo de manejo do solo favorece a saúde da planta, que, por sua vez, fica mais resistente às pragas e doenças, diminuindo ou eliminando a necessidade de agrotóxicos.

Um dos maiores desafios da produção é, sem dúvida, em relação ao combate às pragas. Nesse sentido, a camponesa M. G. P. conta que reduziu o uso de agrotóxicos a quase zero, mas que algumas culturas ainda são muito difíceis de produzir sem o uso de algum tipo de veneno, como no caso do pimentão:

O único veneno que a gente ainda usa quando elas (as pragas) não deixam mesmo produzir é a isca pra formiga de roça, porque ela mata uma plantação bem ligeirinho. A gente sabe que não é certo, mas a gente não pode ser agroecológico de verdade porque senão ela não deixa a gente produzir nada, mas eu só uso em último recurso. Eu tendo como combater ela, eu boto a folha de nim ${ }^{1}$ pra ela carregar. (M. G. P., camponesa do Assentamento Novo Horizonte - Tururu-CE, 2014). 
Esse fato representa uma contradição no discurso da entrevistada e também evidencia algo identificado por Piccin e Moreira (2006, p. 306) entre os camponeses do Assentamento Ceres (RS), os quais utilizam a agroecologia muito mais "como uma possibilidade de arranjos produtivos do que como um modo de vida”. Não sendo possível, portanto, desconsiderar a dinâmica que marca socialmente as diversas trajetórias individuais na região. Assim, esse reconhecimento não desqualifica as lutas sociais dos camponeses, e sim valoriza e reconhece os diferenciais associados ao processo de transição.

Nos depoimentos dos outros camponeses entrevistados não houve relatos de uso de agrotóxico em nenhum caso, nem ficou claro se o produto no qual o agrotóxico é utilizado é levado para feira. Dois fatores contribuem para que esse tipo de situação ocorra. O primeiro é a falta de assistência técnica regular e o outro é a ausência de mecanismos de fiscalização. Contudo, é bom lembrar que a transição agroecológica é processo gradual (Caporal; Costabeber, 2000).

Notou-se durante as entrevistas que a negação dos agrotóxicos é um ponto que aparece nos discursos dos produtores e dos consumidores como o que caracteriza a agroecologia. Esse é o argumento mais usado para o convencimento dos clientes nas feiras. Além da questão do uso do agrotóxico, outra ação que para os camponeses os identifica com a Agroecologia é não fazer uso de queimadas.

M. G. P. conta que, mesmo depois de começar a cultivar a terra com base nos princípios da Agroecologia, realizava duas vezes por ano a queima do lixo, o que gerou prejuízos em relação às plantas:

A partir do dia em que eu queimei um lixo e sapecou um pé de carambola, que eu quase chorei, aí o meu genro chegou e me orientou como eu deveria fazer: a senhora vai pegar e vai separar o lixo, pega tudo que não serve pra nada, bota dentro de um tambor, quando o tambor encher num certo lugar a senhora bota fogo, porque aí você vai estragar só o lugar onde está o tambor, a senhora vai queimar menos produto de uma vez e não vai acabar com o seu quintal. (M. G. P., camponesa do Assentamento Novo Horizonte - Tururu-CE, 2014).

O processo de transição agroecológica vai se delineando à medida que se incorporam os aprendizados e as experiências com seus erros e acertos e se aceitam as mudanças. Tentar algo diferente do que faz a maioria das pessoas é sempre um ato de rebeldia e um risco que se 
corre, porém com persistência e com a humildade de se deixar guiar pelos ensinamentos da natureza é possível fazer algo novo e melhor, como conta o camponês Z. J., que depois da oportunidade do curso de formação e de visitas de intercâmbio passou a acreditar que poderia mudar a sua vida e de sua família produzindo de outra maneira.

A dinâmica de construção do conhecimento agroecológico pelos camponeses investigados seguiu a metodologia, descrita por Sosa et al. (2013), do Movimento Agroecológico Camponês a Camponês (MACAC), experienciada em Cuba, sob a coordenação da Associación Nacional de Agricultores Pequeños (ANAP). Essa metodologia propõe a propagação horizontal do conhecimento de forma a instigar os camponeses a experimentarem as técnicas e selecionarem os processos que mais se adaptam a sua realidade. São nesses momentos de socialização e aprendizado que o discurso torna-se prática. O camponês confere os resultados de outros camponeses que já iniciaram o processo de transição agroecológica e se encoraja a substituir as técnicas convencionais e a desenhar o seu próprio agroecossistema. A MCAC traz em si também um princípio importante na cultura camponesa: a reciprocidade. Cada camponês que participa do intercâmbio é convidado a praticar os princípios agroecológicos e, posteriormente, socializar os resultados com outros camponeses num intercâmbio futuro, dessa vez como anfitrião.

Foi após a participação em alguns intercâmbios que a família do senhor Z. J. iniciou a produção agroecológica, com um quintal produtivo e um sistema PAIS. O PAIS traz o mesmo princípio da mandala, sendo mais adaptável ao semiárido, pois no centro é construído um galinheiro, em vez do tanque de água, a fim de se obter fonte de proteína e de renda para a família, além de produzir o adubo para as plantas.

No PAIS a irrigação se dá por gotejamento, cuja fonte é uma caixa d'água localizada a uma altura de três metros. A irrigação por gotejamento economiza água e energia e reduz o trabalho do camponês com irrigação manual.

Apesar das diferenças de forma e técnica dessas tecnologias sociais, os princípios da produção agroecológica são os mesmos nos sistemas agrícolas quintal produtivo, PAIS e mandala, podendo, inclusive, ser complementares e cultivados na mesma área, como no caso do camponês Z. J., que implantou o sistema de produção PAIS dentro do quintal produtivo. 
A forma de círculo permite melhor integração entre galinheiro e horta, melhor visualização do sistema, mesma distancia do galinheiro a todos os pontos de um mesmo círculo e maior aproveitamento do terreno.

Na ocasião do trabalho de campo realizado na área de produção do Z. J., a plantação das hortaliças para comercialização estava temporariamente suspensa em virtude dos efeitos da estiagem. O sistema de irrigação feito a partir de garrafas PET mostra soluções acessíveis aos camponeses para melhorar a produção, que, embora não estivesse ativada por falta d'água, demonstra as alternativas buscadas.

Apesar de a estiagem impossibilitar a irrigação dos cultivos das hortaliças, a produção do quintal não fica completamente comprometida, pois a renda é extraída de outras culturas. Assim, fica evidente a importância da diversidade, bastante lembrada por autores como Caporal e Costabeber (2000), Altieri (2012), Plog (2009), entre outros, que discutem a relação campesinato e agroecologia.

Esse tipo de sistema agrícola revela o valor da diversidade para a soberania alimentar e econômica da família. O camponês Z. J. conta que diversifica a produção com outras atividades, como a apicultura, por exemplo. Além da produção de mel de abelha italiana, o Sr. Z. J. produz mel de abelha jandaíra, uma espécie mais rara. Ele também comercializa mudas de plantas nativas para um projeto de reflorestação, patrocinado pela Petrobrás, e com isso consegue manter sua renda estável mesmo em período de seca.

Além das hortaliças e da produção de mudas, o quintal da família de Z. J. conta com inúmeras espécies de fruteiras, como mamão, acerola, abacaxi, ata, goiaba, uva, entre outras; espécies de plantas ornamentais e de plantas medicinais; e com espécies de raízes que representam a cultura local, como a macaxeira. O quintal conta também com a criação de galinhas caipiras. O que não é utilizado para a alimentação da família é levado para as feiras agroecológicas e solidárias nas cidades de Itapipoca e de Trairi.

O trabalho é dividido entre o casal e uma filha, a única de seis filhos que reside no assentamento. Conforme Marinho (2016) e Oliveira e Sampaio (2017) a produção agroecológica também tem sido bastante desenvolvida nas escolas do campo, o que garante a aproximação dos jovens com os conhecimentos tradicionais do campesinato e com as novas tecnologias sociais, sobretudo, voltadas para a recuperação de solos e 
produção agrícola. Se antes o único caminho parecia ser o êxodo rural, hoje encontramos jovens camponeses comprometidos com a transição agroecológica no campo.

Na ocasião do trabalho de campo realizado, o camponês Z. J. mostrou a matéria orgânica acumulada no seu quintal e fez questão de explicar sobre a importância daqueles restos de plantas para o equilíbrio do agroecossistema:

Isso aqui é composto, porque aqui ninguém queima. Aqui fica se decompondo e quando é no tempo de plantar, eu pego e tiro esse aqui de cima e esse aqui de baixo e cubro os canteiros de produção. Em vez de comprar outra coisa, a gente usa daqui mesmo. Por isso que sempre eu digo que a natureza é rica, e a gente não sabe de onde é que vem. Uma coisa que a natureza quer receber é a vida, você não queira saber quantos insetos não têm aqui de baixo, quantas vidas não têm aqui, aí eu toco fogo, quantas vidas eu não eliminei? (Z. J., camponês do Assentamento Várzea do Mundaú- Trairi-CE, 2014).

O depoimento do camponês revela uma lição importante na qual se baseia a Agroecologia: a natureza possui mecanismos eficientes de geração da vida e equilíbrio da biodiversidade. É preciso compreendê-los e se convencer de que não se pode intervir em todos os processos, mas que é possível extrair o melhor que a terra tem a oferecer.

\section{Considerações finais}

A Agroecologia significou para os camponeses estudados a esperança de tirar da terra o sustento necessário para sua família, possibilitando sua permanência no campo. Somado a isso, a prática da agricultura agroecológica trouxe consigo a valorização do camponês enquanto agricultor, trabalhador da terra, que tem a consciência de que suas práticas agrícolas são também formas de resistência contra as imposições do Capital e expressam o seu posicionamento político perante a sociedade.

Durante os trabalhos de campo nas unidades de produção, constatou-se que o camponês lança mão dos conhecimentos adquiridos de modo crítico e investigativo, fazendo testes e aperfeiçoando as técnicas, a fim de adaptá-las à realidade.

O grupo investigado encontra-se em "fase de transição agroecológica" (Batista, 2004, p. 53), a qual é marcada pela gradativa substituição dos 
agrotóxicos por defensivos naturais e por práticas de manejo do solo que visam sua recuperação, como a ausência de queimadas e a preservação da cobertura morta. Embora alguns desafios ainda persistam, como a utilização de agrotóxico em alguns casos, muitos resultados já foram alcançados, como o aumento da diversidade de culturas e da produtividade, melhoria nas condições do solo e consequentemente na alimentação e na renda das famílias envolvidas.

\section{Nota}

1 Planta de nome científico Azadirachta Indica A Juss. A folha de nim é um repelente natural de vários insetos.

\section{Referências}

ALTIERI, M. Agroecologia. 3. ed. São Paulo: Expressão Popular, 2012.

BATISTA, M. A. S. Questão agrária e campesinato. 2014. 108 f. Dissertação (Mestrado)-Programa de Pós-Graduação em Geografia, Universidade Federal do Ceará, Fortaleza, 2014. Disponível em: <http://www.repositorio.ufc.br/handle/ riufc/17758>. Acesso em: 09 set. 2018.

CAPORAL, F. R.; COSTABEBER, J. A. Agroecologia e sustentabilidade. In: WORLD CONGRESS OF RURAL SOCIOLOGY, 2000, Rio de Janeiro. Anais... Rio de Janeiro: IRSA, 2000. Disponível em: < http://coral.ufsm.br/ desenvolvimentorural/textos/13.pdf>. Acesso em: 03 jul. 2013.

DUFUMIER, M. Os organismos geneticamente modificados (OGMS) poderiam alimentar o terceiro mundo? In: ZANONI, M. FERMENT, G. (Org.). Transgênicos para quem? Agricultura, Ciência e Sociedade. Brasília: MDA, 2011. p. 368-405.

GLIESSMAN, S. R. Agroecologia. Porto Alegre: UFRGS, 2000.

MARCOS, V. Agroecologia e campesinato. Agrária, São Paulo, n. 7, p. 182210, dez. 2007. Disponível em: <http://www.revistas.usp.br/agraria/article/ view/134>. Acesso em: 10 out. 2017.

MARINHO, G. Sem Terra usam a criatividade para desenvolver experiências educacionais no Ceará. Movimento dos Trabalhadores Rurais Sem Terra. [S. 1.], 17 jan. 2016. Disponível em: <http://www.mst.org.br/2016/01/27/ao-som-daslatas-a-horta-madala-sem-terra-desenvolvem-experiencias-educacionais-no-ce. html>. Acesso em: 07 jan. 2017.

OLIVEIRA, A. M.; SAMPAIO, A. J. M. Escola Camponesa. Revista Nera, Presidende Prudente, ano 20, n. 37, p. 154-168, maio/ago. 2017. Disponível em: <http://revista.fct.unesp.br/index.php/nera/article/view/4989>. Acesso: 08 out. 2017 
PICCIN, M. B. e MOREIRA, R. J. A agroecologia nas trajetórias sociais de agricultores-assentados na Granja menina dos olhos dos sem-terra. Revista Estudos Sociedade e Agricultura, Rio de Janeiro, v. 14, n. 2, p. 254-311, out. 2006. Disponível em: <https://revistaesa.com/ojs/index.php/esa/article/view/278>. Acesso em: 06 ago. 2018.

PLOG, J. D. VAN DER. Sete teses sobre a agricultura camponesa. In: PETERSON, P. (Org.). Agricultura familiar camponesa na construção do futuro. Rio de Janeiro: AS-PTA, 2009. p. 17-32. Disponível em: <http://aspta.org.br/wp-content/ uploads/2011/05/N\%C3\%BAmero-especial.pdf>. Acesso em: 18 jul. 2013.

ROSSET, P. Las recetas no funcionan lo que se propone son princípios. Grain Org. [S. l.], 24 nov. 2016. Disponível em: <https://www.grain.org/es/article/ entries/5600-las-recetas-no-funcionan-lo-que-se-propone-son-principios $>$. Acesso em: 18 out. 2017.

SCHNEIDER, M. Entre a agroecologia e a fumicultura. Etnográfica [Online], v. 18, n. 3, p. 651-669, out. 2014. Disponível em: <http://etnografica.revues.org/3855>. Acesso em: 10 out. 2017.

SOSA, B. M.; JAIME, A. M. R.; LOZANO, D. R. A.; ROSSET, P. M. Revolução agroecológica. 2. ed. São Paulo: Expressão Popular, 2013. Disponível em: < <http:/www.reformaagrariaemdados.org.br/sites/default/files/ Revolucaoagroecologica_ligera.pdf>. Acesso em: 18 set. 2018.

STÉDILE, J. P.; CARVALHO, H. M. Soberania Alimentar. In: CALDART, R. S.; PEREIRA, I. B.; ALENTEJANO, P.; FRIGOTTO, G. (Org.). Dicionário da Educação do Campo. Rio de Janeiro, São Paulo: Expressão Popular, 2012. p. 714723. Disponível em: <http://www.epsjv.fiocruz.br/sites/default/files/l191.pdf>. Acesso em: 18 set. 2018.

TOLEDO, V. A agroecologia é uma revolução epistemológica. Revista Agriculturas, v. 13, n. 1, p. 42 - 45, mar. 2016. Disponível em: <http://aspta.org. br/revista-agriculturas/>. Acesso em: 10 nov. 2017.

Maria Aline da Silva Batista - Graduada e mestre em Geografia, pela Universidade Federal do Ceará. Atualmente é doutoranda do Programa de Pós-Graduação em Geografia da UFC e servidora pública do Instituto Federal de Educação, Ciência e Tecnologia do Ceará. Código ORCID: https://orcid.org/0000-0002-9211-8481.

Alexandra Maria de Oliveira - Graduada pela Universidade Federal do Ceará com Mestrado em Geografia pela Universidade Federal de Sergipe e Doutorado em Geografia Humana pela Universidade de São Paulo. Atualmente é professora da Universidade Federal do Ceará. Código ORCID: https://orcid. org/0000-0002-1698-5436 
Contribuição dos autores

As autoras ofereceram contribuições científicas e intelectuais no desenvolvimento do artigo. As tarefas de concepção do estudo, preparação e redação do manuscrito, bem como revisão crítica foram desenvolvidas em conjunto. A Maria Aline da Silva Batista ficou responsável pela sistematização de dados, interpretação e análise; a autora Alexandra Maria de Oliveira ficou responsável pela coerência teórico e metodológica do documento.

Recebido para publicação em 15 de setembro de 2018 Aceito para publicação em 23 de outubro de 2018 